\title{
Relations between Subdomains of Home Math Activities and Corresponding Math Skills in 4-Year-Old Children
}

\author{
Diana Leyva *, Melissa E. Libertus and Rebecca McGregor
}

check for updates

Citation: Leyva, D.; Libertus, M.E.; McGregor, R. Relations between Subdomains of Home Math Activities and Corresponding Math Skills in 4-Year-Old Children. Educ. Sci. 2021, 11, 594. https://doi.org/10.3390/ educsci11100594

Academic Editor: Fien Depaepe

Received: 24 August 2021

Accepted: 22 September 2021

Published: 29 September 2021

Publisher's Note: MDPI stays neutral with regard to jurisdictional claims in published maps and institutional affiliations.

Copyright: (c) 2021 by the authors. Licensee MDPI, Basel, Switzerland. This article is an open access article distributed under the terms and conditions of the Creative Commons Attribution (CC BY) license (https:/ / creativecommons.org/licenses/by/ $4.0 /)$.
Psychology Department, University of Pittsburgh, Pittsburgh, PA 15260, USA; libertus@pitt.edu (M.E.L.); rem166@pitt.edu (R.M.)

* Correspondence: dml114@pitt.edu

\begin{abstract}
Most studies on the subject have investigated relations between home math activities and child math skills, without paying much attention to the specific skills that such activities foster and their alignment with children's math assessments. The present study examined specific relations between subdomains of home math activities and children's corresponding math skills (e.g., home counting/cardinality activities related to children's counting/cardinality skills). Participants were 78 mostly middle-income, White parents and their four-year-old children ( $M$ age $=53.19$ months; $45 \%$ girls). Parents completed a 24-item survey about the frequency of home activities supporting five subdomains of math: counting/cardinality, set comparison, number identification, adding/subtracting, and patterning. Children's skills in these same five subdomains were assessed using the Preschool Early Numeracy Scale (PENS) and the Early Patterning Assessment. Specific relations were observed in set comparison, adding/subtracting, and patterning, such that higher frequency of home activities in these subdomains related to advanced child math skills in the corresponding subdomains. No specific relations were found in counting/cardinality and number identification. Overall home math activities averaged across the five math subdomains positively related to children's overall math skills. Findings highlight the importance of engagement in specific math activities in the home environment and their significance for corresponding child math development.
\end{abstract}

Keywords: home environment; parenting; preschool; math

\section{Introduction}

Children's math skills at school entry are one of the strongest predictors of later academic achievement [1]. One of the factors that have been proposed to influence such skills are the experiences of the children with math-related activities at home [2]. Despite the widespread notion that home math activities are beneficial for children's early math development, empirical studies on the relations between home math activities and children's math skills reveal mixed results [3]. Many studies find positive relations [4-8]; however, some others find no associations [9-12] or even negative associations [13,14]. In their review of the literature [15], Elliott and Bachman identified, among others, two themes constraining research in this area: (1) broad assessments of home math activities, whereby home activities with very diverse math foci are clustered into one or two composite measures, and (2) broad assessments of children's math skills, whereby skills belonging to diverse math subdomains are clustered into a single composite measure.

We sought to address these two shortcomings of previous studies by asking parents to report about specific home activities by subdomains of math and assessing children's math skills in these very same subdomains. We then examine the relations between these home math activities and children's math skills. Three prior studies have examined math subdomain relations $[11,16,17]$. However, these studies have grouped several skills (i.e., counting and cardinality, set comparison, adding and subtracting, number identification) into a single "numeracy" cluster. To our knowledge, this is the first study to "unpack" the numeracy 
cluster and examine subdomain-specific relations between home math activities and children's math skills. By investigating these relations, we aim to advance our understanding of home influences in children's math development which may ultimately guide future intervention studies targeting specific subdomains of children's emerging math skills.

\subsection{Subdomains of Math Skills}

We focus on five subdomains of math skills that are foundational for math development during the preschool years and that have consistently been included in prior literature: counting and cardinality, set comparison, number identification, adding and subtracting, and patterning $[18,19]$. Below, we briefly review the literature on each skill.

\subsubsection{Counting and Cardinality}

The skills of counting and cardinality represent a child's ability to recognize the oneto-one correspondence between numbers and sets of objects, the stable order of numbers in a counting sequence, and the idea that the last number in a counting sequence is the value of that set. Initially, children may have memorized the list of number words, but they do not understand the meaning of the words. That is, when asked to give one object, they may hand any number of objects. Around 2.5 years of age, children start to understand the meaning of "one" and reliably give one object when asked for it. However, it takes most children several more months to arrive at an understanding of the word "two" and even after that several more months before they understand the word "three" [20]. Children have grasped the concept of cardinality when they understand that adding one more object means counting to the next number [21]. Children who develop the cardinality principle within the first year of preschool (age 3) have higher math achievement in first grade than children who develop this skill in kindergarten [22]. Furthermore, preschool children (4- to 5-year-olds) with better counting and cardinality skills have more advanced adding and subtracting skills [23]. Finally, advanced counting skills in preschool, like counting backward, are also one of the best predictors of fifth grade math achievement [24].

\subsubsection{Set Comparison}

When children learn to compare groups of objects using words like "more", "less", "most", and "least", they are developing an understanding of ordinal relations between quantities. These skills can develop separately from other foundational math skills (i.e., counting and number identification), as it is not necessary to know the exact number of objects in each group to successfully compare two groups [25]. Research with 3- to 5-yearold children shows that children's set comparison skills positively relate to their numbering (i.e., counting and cardinality) and arithmetic skills (i.e., adding and subtracting) [26] In addition, children's set comparison skills in kindergarten predict their arithmetic skills in first grade and fact retrieval in second grade [27]. Though studies associating children's comparison skills with general math skills are mixed, meta-analytic reviews have found small but significant effects between these factors [28,29].

\subsubsection{Number Identification}

Number identification is the process of connecting a written number (e.g., 5) to a verbal word (e.g., five). By understanding how to recognize written numbers, children can apply their verbal counting and comparison skills to solve problems and process important information in their surroundings [30]. Number identification skills are related to other early numeracy skills, even tasks that do not include numbers such as matching sets of objects with equivalent quantities [31]. Children's number identification skills in preschool positively relate to counting and cardinality and adding and subtracting skills [32]. Moreover, the ability to recognize numbers positively relates to children's math achievement in preschool [33] and to adding and subtracting skills in first grade [34]. 


\subsubsection{Adding and Subtracting}

Once children understand the concepts of counting and cardinality, they are prepared to develop basic arithmetic skills like adding and subtracting. These skills then equip children to develop more complex arithmetic skills like multiplication and division. Many preschool children are able to solve simple addition and subtraction problems, but there is also evidence that they can understand the concepts of addition and subtraction of large groups of objects beyond their counting abilities [35,36]. Adding and subtracting skills then continue to become more complex as children move through school. Kindergarten children's arithmetic skills positively relate to their math achievement through third grade [30].

\subsubsection{Patterning}

In recent years, researchers have called to move beyond numeracy and broaden our conceptualization of math skills [11,12]. One of the most common skills included in this broader concept of math is patterning. When children learn to recognize and complete patterns, they deepen their problem-solving abilities. Preschool children's patterning skills positively relate to their concurrent general math knowledge in preschool $[37,38]$ and are predictive of their math achievement in fifth grade [24,39]. Patterning helps children form generalizations, and this ability is foundational for algebraic thinking [24].

\subsection{Home Math Activities and Children's Math Skills}

Below we review the three most common frameworks used in the prior literature to conceptualize home math activities and include information on the data analytic methods utilized and the number of items included. We also include information on whether the studies tested associations with a composite measure of children's math skills or specific math subdomain skills. Our study aims to address these two themes by paying closer attention to specific subdomains of math in both surveys of home math activities and children's math assessments instead of primarily targeting math broadly [15].

\subsubsection{Home Math Activities as a Single Factor}

Some studies have relied on empirical methods (i.e., principal component analysis) to conceptualize home math activities as a single factor. For example, a study of 5- to 7-year-olds in the Netherlands found a single factor called "parent-child numeracy activities" involving four items (three of which were about frequency of counting activities, and one was about frequency of set comparison activities), which positively related to children's math skills, a composite score entailing, among other skills, counting, and set comparison [6]. Another study of 5- to 7-year-olds in Greece found a single factor called "parent numeracy teaching" involving five items (frequency of home activities involving number identification, counting, set comparison, and adding/subtracting), which positively related to children's counting skills, but not to math concepts (e.g., cardinality) or math fluency (i.e., set comparison, adding/subtracting) [8]. Yet another study of 5- to 8-year-olds in the Philippines found a single factor called "home numeracy activities" involving 12 items (frequency of activities involving counting, number identification, adding/subtracting and set comparison, among others), which positively related to children's math skills, a composite measure of counting, number identification, set comparison and addition [40].

\subsubsection{Home Math Activities as Two Factors: Formal and Informal}

In contrast, other studies used principal component analysis and conceptualized home math activities as two factors: formal (direct teaching) versus informal (indirect teaching). For example, a study of 5- to 7-year-olds in Canada found four factors involving 17 items: two factors reflecting formal activities (i.e., number practices, number books) and two factors reflecting informal activities (i.e., games, applications). One of the factors of informal activities (i.e., games) positively related to children's math skills, a composite measure of number identification, counting, set comparison, and addition and subtraction [4]. The same four factors involving 16 items were identified in a study of 4- to 6-year-olds 
in Belgium [41]. One of the factors of formal activities (i.e., number practices) positively related to children's counting skills, while one of the informal activities (i.e., applications) positively related to children's calculation and symbolic number line estimation. Based on this framework, another study of 5- to 6-year-olds in Canada used separate assessments for formal and informal activities [5]. For formal activities, they found two factors involving 13 items, one of which (i.e., advanced formal activities) positively related to children's math skills, a composite measure of number identification, counting, set comparison, and addition and subtraction. For informal activities, a mean score was used (based on a survey about number game exposure), which positively related to children's ability to add and subtract without relying on numerals (non-symbolic arithmetic). Others have adopted this framework but have not utilized data analytic methods to draw such factors. For example, a study of 3- to 5-year-olds in the U.S. grouped responses to items into six types of activities and found that one of these types (i.e., formal activities) positively related to children's counting and number identification but not to other skills such as cardinality and set comparison [42].

\subsubsection{Home Math Activities as Mean/Sum Score}

Finally, some studies have utilized confirmatory factor analysis and found that neither a 1-factor (overall home math activities) nor a 2-factor (formal and informal activities) solution were a good fit to their data (e.g., [12]). Thus, these studies have conceptualized home math activities as a mean frequency or sum score across items (ranging from 3 to 36) involving activities promoting counting/cardinality, adding/subtracting, set comparison, number identification and patterning, among others. In doing so, the studies assume that items represent observed variables (i.e., equal item weights) rather than latent variables (i.e., differential item weights, like principal component analyses do). Some of these studies have found no relations between mean frequency scores of home math activities and a composite measure of children's math skills (4- to 6-year-olds in the U.S.: [9]; 2- to 4-year-olds in the U.S.: [10]; 3- to 5-year-olds in the U.S.: [12]; 5- to 6-year-olds in Belgium: [11]). Others have found positive relations. For example, one study of 5- to 7-year-olds in Germany conceptualized home math activities as a sum score (three items; frequency of playing games involving dice, counting, and calculation) and found positive associations to children's math skills, a sum score of several tasks assessing counting, number identification, set comparison and adding/subtracting [7].

Taken together, prior studies have substantially varied in the number of items included in their home math surveys (from 3 to 36) and have typically utilized empirical methods (e.g., principal component analysis, confirmatory factor analysis, mean/sum scores) to guide their conceptualization of home math activities. In addition, most studies have assessed subdomains of children's math skills but have ultimately grouped them into a single composite score when examining relations between home math activities and children's math skills. Thus, it is unclear whether taking a different approach to conceptualizing home math activities grounded conceptually in the subdomain of math skill that the respective activities foster and testing subdomain relations between home math activities and children's corresponding math skills (e.g., whether home activities fostering adding/subtracting relate to children's adding/subtracting skills), can complement and further our understanding of the role that the home environment plays in children's math development.

The idea of examining subdomain relations between home math activities and children's math skills is grounded in work conducted in the domain of language and literacy [43-45], whereby home learning activities are conceptualized based on the type of skills fostered rather than other variables (e.g., direct versus indirect teaching by parents). This may also be the way that parents rationalize providing math support to their child, choosing to focus on a particular activity because their child struggles with the skill rather than providing math support more generally. By taking this approach, we aimed to disentangle the complex relations between home environment and children's math development. Others have called for similar nuanced approaches [11,16,17]. For example, one study avoided aggregating children's math skills into a single composite score but rather used separate scores; however, home math 
activities were still parsed into formal versus informal factors [41]. Because different home math activities promote different math skills, a fine-grained characterization of the relations between subdomains of home math activities and children's math skills is warranted.

\subsection{Current Study}

The aim of the current study is to examine the relations between home math activities and 4-year-old children's math skills. We addressed two research questions:

(1) What are the relations between frequencies of home math activities by subdomain?

Overall, we expected positive associations across frequencies of home math activities, but examined the strength of such associations (weak, moderate, or strong). For example, parents who engaged in more home number identification activities would also engage in more home adding/subtracting activities. It was important to examine this question to rule out the possibility that subdomains of home math activities were highly intercorrelated (i.e., multicollinearity issues), suggesting they belong to a single construct.

(2) Are there specific associations between subdomains of home math activities and 4-year-old children's skills in the corresponding subdomain of math?

We hypothesized positive associations between specific home math activities and 4-year-olds' skills in the corresponding subdomain of math. For example, high frequency of home counting/cardinality activities would relate to advanced children's counting/cardinality skills, high frequency of home set comparison activities would relate to advanced children's set comparison skills, and so forth.

\section{Materials and Methods}

\subsection{Participants}

Data were drawn from a larger project that tested the potential efficacy of a home math intervention. All data included in the current study were collected before families participated in any intervention activities. Participants for this study were 78 four-year-old children $(M$ age $=53.19$ months, $\mathrm{SD}=3.41$, range $=48-60 ; 45 \%$ girls $)$ and one of their parents ( $96 \%$ mothers; $M$ parent's age $=36.49$ years, $\mathrm{SD}=3.82$, range $=28-47$ ), who had complete home math environment and child math skills data before the intervention. Parents' highest level of education was as follows: $56.41 \%$ had a graduate degree, $30.77 \%$ completed 4-year college, $7.69 \%$ started 4-year college, 3.85\% completed 2-year college, and $1.28 \%$ started 2-year college. Parents' ethnicity was as follows: $85.90 \%$ were White, $5.13 \%$ were Asian, 3.85\% were Black/African American, 2.56\% were multi-racial, $1.28 \%$ were Hispanic/Latino, and $1.28 \%$ were American Indian/Alaska Native. Parents were recruited via an online research platform, flyers distributed in preschools, social media advertising, and word of mouth. To be eligible, families had to have a child who was four years old at the start of the study and did not have an intellectual or learning disability, live in the United States, speak, read, and write English fluently, and be comfortable being recorded on a videoconference call with their child. All parents gave written informed consent as approved by the local Institutional Review Board prior to the start of any research activities.

\subsection{Procedure and Measures}

All data from this study were collected virtually due to restrictions to in-person research activities during the COVID-19 pandemic. Parents were emailed a link to complete an online survey about their demographic information (e.g., child age and sex and parents' education) and home math environment (see below for more details). Children were asked to complete several math assessments administered via a videoconference call approximately 5 days after the online survey link was sent. If the surveys were not yet complete at the time of the conference call, the parent was reminded during the call or via email to complete them. If the parent did not complete the surveys one week and a half after they were reminded to do so, their survey data were considered missing. During the videoconference call, the parent was asked to stay in the room while the child 
completed the math assessments in case there were any technical issues but not to provide any encouragement, prompts, or help to the child.

\subsubsection{Home Math Environment}

Parents completed a 30-item survey reporting how often they and their child engaged in several home math activities during a typical week using a 4-point scale from 1 (not at all), to 2 (once per week), to 3 (several times a week), to 4 (every day). See Appendix A for a full list of items. Out of the 30 items, five items involved counting and cardinality (e.g., count by something other than 1s, like 2s, 5s, or 10s), seven items involved set comparison (e.g., use terms 'more' and 'less'), two items involved number identification (e.g., note numbers on signs when driving/walking), six items involved adding and subtracting (e.g., add and subtract to 10), and four items involved patterning (e.g., duplicate simple patterns). Six additional items involved activities that did not fall into any of the previous subdomains; thus, they were not included in the study (e.g., using calendars and dates). The 30-item survey was created by compiling items from previous studies $[4,17,46-50]$. Parents also had the option of responding "my child is too old/young for this activity". Thirty-five percent of parents chose this response for at least one of the 24 items included in this study, with no one using this option for more than nine items. There was high item reliability for all math subdomains $(\alpha=0.80-0.86)$, except for counting/cardinality $(\alpha=0.37)$, which might be because we grouped counting/cardinality activities with different levels of complexity and thus very different frequencies of occurrence at home (e.g., counting using fingers is low in complexity and presumably more often practiced while counting by $2 \mathrm{~s}$ or $5 \mathrm{~s}$ is high in complexity and presumably less often practiced). We calculated separate average scores for each math subdomain and an overall score (mean score across five subdomains).

\subsubsection{Child Math Skills}

We assessed children's math skills in the same five subdomains assessed in the home math environment survey: counting/cardinality, set comparison, number identification, adding/subtracting, and patterning. For the first four subdomains, we used selected items from the following subscales of the Preschool Early Numeracy Scale (PENS) [19]: One-to-One Counting/Cardinality (five items), Set Comparison (four items), Numeral Identification (five items), and Story Problems (four items). All stimuli were presented for as long as necessary for the child to respond to the item. For the One-to-One Counting/Cardinality items, the child was shown sets of six to 18 dots and asked to count them and say how many dots there were. For the Set Comparison items, the child was shown sets of zero to 12 dots with four sets presented at a time and asked which set had the most/least dots. For the Set Comparison items, the child was allowed (but not instructed) to count the dots to determine which set had more/less. In the Numeral Identification items, the child was shown single- and double-digit numerals (numerals $\leq 20$ ) and asked to name them. In the Story Problems items, the child was verbally told stories involving simple addition or subtraction problems with numbers from 0 to 4 and asked to solve them.

In addition, we used six items taken from the Early Patterning Assessment [51] for the patterning subdomain. The first two items focused on pattern identification; the child was shown a set of colored squares and asked: "Is this a pattern?" The next two items focused on missing patterns; the child was shown a pattern made of images, was asked "What is missing in the pattern?" and was provided with three possible solutions to choose from. The last two items focused on extending patterns; the child was shown a pattern made of images, asked "What comes next in the pattern?", and provided with three possible solutions to choose from. There was also one practice item on pattern identification and one practice item on missing patterns that the child completed before these sections. After answering a practice question, the child was told whether they were correct or incorrect and a justification for why they were correct or incorrect. 
The child received a score of " 1 " for every correct answer in each of the assessments, and a score of " 0 " otherwise. For each of the five math subdomains, we first calculated the total number of correct answers. There was moderate to high item reliability for all math subdomains $(\alpha=0.55-0.83)$, except for patterning $(\alpha=0.31)$. To compare scores across math tasks with different numbers of items, we calculated the percent correct of total items for each domain and used them in analyses. We also calculated an overall child math skills score (average percentage correct of items across the five subdomains).

\section{Results}

\subsection{Preliminary Analysis}

Table 1 shows the descriptive statistics for home math activities and child math skills. There was substantial variability in the frequency with which parents engaged in home math activities; while some indicated never engaging in some math activities, others indicated engaging in such activities every day. On average, parents reported engaging in number identification activities several times per week, whereas they engaged in all other home math activities (counting and cardinality, set comparison, adding and subtracting, and patterning) on average only once per week. Similarly, there was wide variability in children's math scores. While some children got zero correct answers in some math domains, others got all answers correct. On average, children had between $50-70 \%$ correct answers across math domains. Data were normally distributed with skewness statistics ranging from -0.31 to 0.63 for home math environment and -0.64 to 0.23 for child math skills. Table 2 shows results of Pearson's correlations testing for associations among child math skills. Weak to moderately strong associations were found among counting and cardinality, set comparison, number identification and adding and subtracting. Patterning was positively related to adding and subtracting, and marginally positively related to set comparison, but not to number identification or counting and cardinality.

Table 1. Descriptive Statistics for Home Math Activities and Child Math Skills $(N=78)$.

\begin{tabular}{lcccc}
\hline & Mean & SD & Min-Max & Skewness \\
\hline Home Math Activities & & & & \\
Counting/cardinality & 2.61 & 0.49 & $1.75-4.0$ & 0.4 \\
Set comparison & 2.69 & 0.59 & $1.29-4.0$ & -0.08 \\
Number identification & 3.1 & 0.73 & $1.5-4.0$ & -0.31 \\
Adding/subtracting & 2.11 & 0.76 & $1-4.0$ & 0.63 \\
Patterning & 2.38 & 0.76 & $1-4.0$ & 0.18 \\
Overall home math & 2.52 & 0.47 & $1.66-3.77$ & 0.33 \\
\hline Child Math Skills & & & & \\
Counting/cardinality & 54.62 & 37.13 & $0-100$ & -0.10 \\
Set comparison & 69.55 & 31.12 & $0-100$ & -0.64 \\
Number identification & 65.9 & 31.93 & $0-100$ & -0.43 \\
Adding/subtracting & 50.64 & 32.73 & $0-100$ & 0.02 \\
Patterning & 51.07 & 22.53 & $16.67-100$ & 0.23 \\
Overall math skills & 57.91 & 20.44 & $16.67-100$ & -0.06 \\
\hline
\end{tabular}

Note. Frequency of home math activities is reported using a 4-point scale from 1 (not at all), to 2 (once per week), to 3 (several times a week), to 4 (every day). Child math scores represent percentage of correct answers.

Table 2. Results of Pearson's Correlations Examining Associations Among Child Math Skills.

\begin{tabular}{|c|c|c|c|c|c|}
\hline Child Math Skills & 1 & 2 & 3 & 4 & 5 \\
\hline 1. Counting/cardinality & - & & & & \\
\hline 2. Set comparison & $0.35^{* *}$ & - & & & \\
\hline 3. Number identification & $0.50^{* * *}$ & $0.39^{* * *}$ & - & & \\
\hline 4. Adding/subtracting & $0.23 *$ & $0.41^{* * *}$ & 0.25 * & - & \\
\hline 5. Patterning & 0.13 & $0.21+$ & 0.18 & $0.34^{* *}$ & - \\
\hline
\end{tabular}




\subsection{Relations among Home Math Activities}

We performed Pearson's correlations to determine relations across home math activities. Table 3 shows the results of these analyses. Associations among home math activities varied based on the activities involved. Of the ten associations tested, five of them were moderate ( $r$ r ranging from 0.32 to 0.47 ), three were weak ( $r$ s ranging from 0.20 to 0.29 ), one was strong $(r=0.67$; set comparison and adding and subtracting), and one was non-significant $(r=0.14$; counting and cardinality and patterning). Thus, most home activities were positively and moderately related, although there was wide variability in the strength of such associations.

Table 3. Results of Pearson's Correlations Examining Associations Among Home Math Activities.

\begin{tabular}{lccccc}
\hline \multicolumn{1}{c}{ Home Math Activities } & $\mathbf{1}$ & $\mathbf{2}$ & $\mathbf{3}$ & $\mathbf{4}$ & $\mathbf{5}$ \\
\hline 1. Counting/cardinality & - & & & & \\
2. Set comparison & $0.21+$ & - & & & \\
3. Number identification & $0.29^{* *}$ & $0.32^{* *}$ & - & & \\
4. Adding/subtracting & $0.37^{* * *}$ & $0.67^{* * *}$ & $0.20+$ & - & \\
5. Patterning & 0.14 & $0.47^{* * *}$ & $0.40^{* * *}$ & $0.39^{* * *}$ & - \\
\hline
\end{tabular}

\subsection{Relations between Home Math Activities and Children's Math Skills}

We performed ordinary least squares (OLS) regressions to test for associations between frequency of home math activities (predictor) and children's math skills (outcome), controlling for the following covariates: child age (in months), child sex (coded as dummy variable, the reference group was female) and parents' education (coded as a dummy variable, the reference group was 4-year college education or higher). We conducted separate analyses for each of the five math subdomains.

As can be seen in Table 4, frequency of home activities in a specific subdomain of math was only related to children's corresponding math skill for set comparison, adding and subtracting, and patterning. Specifically, frequency of home set comparison activities positively related to children's set comparison abilities, but not child age, sex, or parent education. Similarly, frequency of home adding and subtracting activities positively related to children's adding and subtracting abilities; in addition, parents' education but not child age or sex positively related to this ability. Frequency of home patterning activities positively related to children's patterning abilities; parents' education but not child age or sex also positively related to children's patterning abilities. In contrast, frequency of home number identification activities and parents' education did not relate to children's number identification performance; child age positively related to this ability and child sex negatively related to this ability, suggesting that boys outperformed girls in this ability. Similarly, frequency of home counting and cardinality activities and child sex did not relate to children's counting and cardinality abilities; only child age and parents' education positively related to this ability. Subsequent analyses regressing children's adding and subtracting skills on home counting/cardinality, set comparison, and number identification activities, controlling for child age, sex, and parent education revealed no significant associations ( $\beta$ s ranging from -0.85 to -0.13 , all $p \mathrm{~s}>0.10$ ) except marginal significance for set comparison activities $(\beta=10.66, p=0.09)$.

To summarize, we found positive specific associations in three out of the five subdomains of math (i.e., set comparison, adding and subtracting, and patterning), such that the more parents reported engaging in activities promoting these specific subdomains, the more advanced children's skills in these domains. Frequency of overall math activities positively related to child's overall math skills, and so did child age and parents' education. 
Table 4. Results of OLS Regressions Examining Associations between Home Math Activities and Child Math Skills.

\begin{tabular}{|c|c|c|c|c|c|c|}
\hline & \multicolumn{6}{|c|}{ Child Math Skills } \\
\hline & $\begin{array}{l}\text { Counting/ } \\
\text { Cardinality }\end{array}$ & Set Comparison & $\begin{array}{c}\text { Number } \\
\text { Identification }\end{array}$ & $\begin{array}{l}\text { Adding/ } \\
\text { Subtracting }\end{array}$ & Patterning & $\begin{array}{c}\text { Overall } \\
\text { Math }\end{array}$ \\
\hline \multicolumn{7}{|l|}{ Predictor } \\
\hline Specific home math activity ${ }^{a}$ & $\begin{array}{l}14.72 \\
(8.04)\end{array}$ & $\begin{array}{l}17.21 * * \\
(5.57)\end{array}$ & $\begin{array}{c}6.90 \\
(4.87)\end{array}$ & $\begin{array}{c}20.63 * * * \\
(4.51)\end{array}$ & $\begin{array}{l}6.72 * \\
(3.20)\end{array}$ & $\begin{array}{c}13.62 * * \\
(4.40)\end{array}$ \\
\hline \multicolumn{7}{|l|}{ Covariates } \\
\hline Child age & $\begin{array}{l}2.31 * \\
(1.16)\end{array}$ & $\begin{array}{c}1.91 \\
(0.96)\end{array}$ & $\begin{array}{l}2.54^{*} \\
(1.02)\end{array}$ & $\begin{array}{l}-1.08 \\
(1.01)\end{array}$ & $\begin{array}{l}1.39 \\
(0.71)\end{array}$ & $\begin{array}{l}1.51 * \\
(0.60)\end{array}$ \\
\hline Child female & $\begin{array}{l}10.59 \\
(7.85)\end{array}$ & $\begin{array}{l}-0.02 \\
(6.54)\end{array}$ & $\begin{array}{l}-15.77 * \\
(7.07)\end{array}$ & $\begin{array}{l}-6.71 \\
(6.48)\end{array}$ & $\begin{array}{l}1.89 \\
(4.88)\end{array}$ & $\begin{array}{l}-1.76 \\
(4.05)\end{array}$ \\
\hline Parent has $\geq$ college degree & $\begin{array}{l}28.45^{*} \\
(11.64)\end{array}$ & $\begin{array}{l}14.23 \\
(9.70)\end{array}$ & $\begin{array}{c}6.44 \\
(10.30)\end{array}$ & $\begin{array}{l}27.24 * * \\
(10.08)\end{array}$ & $\begin{array}{l}15.69^{*} \\
(7.20)\end{array}$ & $\begin{array}{c}17.21^{* *} \\
(6.00)\end{array}$ \\
\hline
\end{tabular}

Note. Unstandardized Betas (SE in parenthesis) are reported. ${ }^{*} p<0.05,{ }^{* *} p<0.01,{ }^{* * *} p<0.001 .{ }^{\text {a }}$ Specific home math activity $=$ we conducted separate analysis for each math subdomain; for example, we tested whether home counting/cardinality activities related to children's counting/cardinality skills.

\section{Discussion}

We examined whether there were subdomain relations between home math activities and 4-year-old children's corresponding math skills. By focusing on five different subdomains of math skills, we aimed to address previous concerns about broad assessments of home math activities and children's math skills, as two main themes constraining research in this area [15]. In doing so, we aimed to help disentangle the complex relations between the home math environment and children's math development. We found variability in the strength of the associations among home math activities. We also found positive associations between home math activities and children's corresponding math skills in three out of the five subdomains of math (i.e., set comparison, adding and subtracting, and patterning). Below we elaborate on each finding.

The strength of the associations among home math activities fostering diverse subdomains of math skills was variable. Some associations were non-significant or weak. For example, parents who reported engaging in home activities fostering counting and cardinality were not necessarily engaging in activities fostering patterning. Many associations were positive and moderate. For example, parents who reported engaging in activities fostering counting and cardinality also engaged in activities fostering adding and subtracting. Only one association was positive and strong; the more parents reported engaging in set comparison the more they reported engaging in adding and subtracting. Together, our findings indicate that there was variability in the frequency with which parents engaged in home math activities, which replicates the results of many previous studies [4,5,8,41]. Parents were not necessarily engaging in home math activities supporting all five subdomains of math skills. Instead, parents seemed to engage in home activities supporting certain math skills over others. Possible explanations for these findings could be that home math activities are driven by parents' beliefs about how children develop math skills during preschool, their view about the role they play in their children's learning, and their own math experiences and abilities (for a review see [3]). Alternatively, children's abilities and interests may influence what math activities parents and children engage in. These findings support the need to examine separate subdomain associations of home math activities and children's math skills.

Parents who reported frequently engaging in home math activities promoting adding and subtracting had children with advanced adding and subtracting skills. Notably, parents reported engaging in home activities supporting this math skill least often across the five subdomains and children had the lowest scores on these math skills. It is possible that many parents did not view adding and subtracting activities as developmentally appropriate skills to foster with their preschool children, so the children of parents that did engage in these activities at home were able to significantly develop and strengthen these skills. Alternatively, children who did not have a good grasp of addition and subtraction yet 
may have showed less interest in home activities related to adding and subtracting or the necessary skills to engage in these activities. Similar findings were observed in set comparison, with parents who reported frequently engaging in home math activities promoting these skills having children with advanced set comparison skills.

Additionally, parents who reported engaging more frequently in home math activities promoting patterning had children with advanced patterning skills. In prior research, no associations have been found between the frequency of home math activities and children's patterning skills $[11,12,16]$. Researchers explained this lack of associations via the low frequency with which parents reported engaging in such activities (i.e., less than once per week) compared to other math activities (i.e., once per week or more than once per week). In our study, the frequency with which parents engaged in patterning activities was relatively low (once per week), but it was not any lower than those of other math activities (e.g., adding and subtracting, counting and cardinality). Importantly, in some prior research [11,12] a composite measure of home math activities (across subdomains of math skills) was used, which might have prevented researchers from finding associations to children's patterning skills. In other prior research [16], items administered to parents included both patterning activities (which tend to happen once per week) and other activities such as watching TV shows involving patterns (which tend to happen several times per week) [52]. This clustering of activities that happen at different frequencies and across different formats (e.g., active vs passive engagement) might have prevented researchers from finding associations. In our study, we focused only on the former (i.e., patterning activities). In future research, it would be important to further investigate why these three subdomains of math skills yielded positive relations, while other subdomains that are known to be foundational to math development, such as number identification, or counting and cardinality, did not yield positive associations. One possible explanation may be that number identification and counting/cardinality are subdomains of math that are more heavily emphasized in preschool curricula [53], such that the home environment plays less of a role in children's development of these math skills than for the other subdomains.

Demographic factors also related to children's skills in certain math subdomains. Child age positively related to counting and cardinality, number identification and overall math. Child sex (female) negatively related to number identification skills. Parents' education positively related to all math subdomain skills, except set comparison and number identification. Overall, these findings align with what prior research has found $[11,17]$. It would be important to replicate these findings with a larger and more diverse sample to further understand why some demographic factors but not others relate to certain math subdomains and not others.

Taken together, our findings are promising because they might indicate that when specific subdomains of math skills are examined, positive associations between home math activities and corresponding math skills are more likely to be detected, at least in some subdomains of math skills, such as adding and subtracting, set comparison, and patterning, than when composite measures of home math activities are utilized. These findings suggest that future interventions should target subdomain-specific activities to foster development of corresponding subdomains of math.

\section{Limitations}

Our study has some limitations. First, our sample was homogeneous (mostly White, highly educated, and from middle-income backgrounds). It is an open question whether our results generalize to populations with other racial/ethnic and socioeconomic backgrounds. As a result, future studies should aim to replicate these findings with a more diverse sample. Second, we focused on the five most common subdomains of math skills, but others have been assessed, including non-symbolic arithmetic, number line estimation, geometry, and measurement [5,41]. In future work, it would be important to include such skills. Third, we focused on parental self-reports but acknowledge that observations of parent-child interactions are needed to have a complete picture of the quantity and quality 
of the math support provided by parents in these activities. Two recent studies $[54,55]$ have found a lack of associations between parental reports of home math activities and parental math talk during specific math-related activities, suggesting the need to triangulate information about the home math environment across different sources. Fourth, we tested for concurrent associations between home math activities and children's math skills; thus, the directionality of such association is uncertain, and most likely, it is bidirectional. Just like parents influence children's math skills, children's math skills can influence the type and frequency of parental support provided [2]. Like many other studies in this area, the current study also cannot infer causation between home math activities and children's math skills as a result of this concurrent design. Fifth, results are specific to the age range targeted by this study (i.e., 4-year-olds). It is an open question whether similar associations between home math activities and children's math skills are found if a wider preschool age range (3- to 5-year-olds) or older children (kindergarten, first grade) are included. Sixth, these data were collected during the COVID-19 pandemic, which offers a unique reflection of the home numeracy environment that may not generalize to research conducted prior to the start of the pandemic and may not generalize to the future.

\section{Conclusions}

To date, research on the relations between home math activities and children's math skills has yielded mixed evidence, with some studies finding positive associations, while others find null or negative associations [2,3]. Our findings might explain, at least in part, this mixed evidence. When associations between home math activities and children's math skills are examined at the level of subdomains of math skills, we do not find perfect alignment between home math activities and children's math skills in the five subdomains targeted. Home math activities in some subdomains (i.e., adding/subtracting, set comparison, and patterning) were aligned with children's corresponding competences, but others were not. Further fine-grained research is needed to advance our understanding of the complex relations between home math activities and children's math skills, especially focusing on which activities may lend themselves well to be included in interventions aimed at improving children's math skills.

Author Contributions: Conceptualization: D.L., M.E.L. and R.M.; methodology: D.L., M.E.L. and R.M.; formal analysis: R.M. and D.L.; data curation: R.M.; writing-original draft preparation: D.L. and R.M.; writing-review and editing: M.E.L.; funding acquisition: D.L. and M.E.L. All authors have read and agreed to the published version of the manuscript.

Funding: This project was supported by an internal grant from the Learning Research and Development Center (LRDC) at University of Pittsburgh. MEL's contributions to this project were further supported by a Scholar Award from the James S. McDonnell Foundation.

Institutional Review Board Statement: The study was conducted according to the guidelines of the Declaration of Helsinki, and approved by the Institutional Review Board (or Ethics Committee) of University of Pittsburgh (protocol code 20110438 and date of approval: 2 September 2021).

Informed Consent Statement: Informed consent was obtained from all subjects involved in the study.

Data Availability Statement: The data presented in this study are available on request from the corresponding author. The data are not publicly available due to privacy restrictions.

Acknowledgments: The authors would like to thank all children and families who participated in this project, the part-time lab coordinator, and the undergraduate student research assistants who made this work possible.

Conflicts of Interest: The authors declare no conflict of interest. 


\section{Appendix A}

Table A1. Home Math Environment Survey.

\begin{tabular}{|c|c|c|c|c|c|c|}
\hline \multicolumn{7}{|c|}{ During a Typical Week, How Often Do You and Your Child: } \\
\hline & & Every Day & Several Times a Week & Once a Week & Not at All & $\begin{array}{l}\text { My Child Is Too Old/Young } \\
\text { for This Activity }\end{array}$ \\
\hline 1. & Count objects & $\square$ & $\square$ & $\square$ & $\square$ & $\square$ \\
\hline 2. & Count down $(10,9,8,7 \ldots)$ & $\square$ & $\square$ & $\square$ & $\square$ & $\square$ \\
\hline 3. & $\begin{array}{l}\text { Count by something other } \\
\text { than } 1 \mathrm{~s} \text {, like } 2 \mathrm{~s}, 5 \mathrm{~s} \text {, or } 10 \mathrm{~s}\end{array}$ & $\square$ & $\square$ & $\square$ & $\square$ & $\square$ \\
\hline 4. & Count using his/her fingers & $\square$ & $\square$ & $\square$ & $\square$ & $\square$ \\
\hline 5. & Counting out money & $\square$ & $\square$ & $\square$ & $\square$ & $\square$ \\
\hline 6. & $\begin{array}{l}\text { Identifying names of } \\
\text { written numbers }\end{array}$ & $\square$ & $\square$ & $\square$ & $\square$ & $\square$ \\
\hline 7. & $\begin{array}{l}\text { Identify numbers as more or } \\
\text { less (e.g., } 7 \text { is more than } 4)\end{array}$ & $\square$ & $\square$ & $\square$ & $\square$ & $\square$ \\
\hline 8. & $\begin{array}{l}\text { Estimate a small number for } \\
\text { small groups and a large } \\
\text { number for large groups } \\
\text { (e.g., estimating } 6 \text { for a small } \\
\text { group of rocks and } 30 \text { for a } \\
\text { large group of rocks) }\end{array}$ & $\square$ & $\square$ & $\square$ & $\square$ & $\square$ \\
\hline 9. & $\begin{array}{l}\text { Note numbers on signs } \\
\text { when driving/walking }\end{array}$ & $\square$ & $\square$ & $\square$ & $\square$ & $\square$ \\
\hline 10. & $\begin{array}{l}\text { Measure ingredients } \\
\text { when cooking }\end{array}$ & $\square$ & $\square$ & $\square$ & $\square$ & $\square$ \\
\hline 11. & Use calendars and dates & $\square$ & $\square$ & $\square$ & $\square$ & $\square$ \\
\hline 12. & $\begin{array}{l}\text { Use numbers in reference to } \\
\text { temperature, time, and dates }\end{array}$ & $\square$ & $\square$ & $\square$ & $\square$ & $\square$ \\
\hline 13. & $\begin{array}{l}\text { Compare groups of objects } \\
\text { to identify more or less or } \\
\text { same/equal }\end{array}$ & $\square$ & $\square$ & $\square$ & $\square$ & $\square$ \\
\hline 14. & Use terms "more" and "less" & $\square$ & $\square$ & $\square$ & $\square$ & $\square$ \\
\hline 15. & Read number storybooks & $\square$ & $\square$ & $\square$ & $\square$ & $\square$ \\
\hline
\end{tabular}


Table A1. Cont.

During a Typical Week, How Often Do You and Your Child:

Every Day Several Times a Week Once a Week Not at All My Child Is Too Old/Young

\section{Play games in the car that} involve math

17. Learn simple sums

(i.e., $2+2=4$ )

18. Add and subtract using objects

19. Recognize how parts make a whole

20. Create equal-sized groups from a larger group (e.g., sharing snacks fairly)

21. Practice adding or taking away from an amount to create more or less

22. See that one object is bigger or smaller than another by directly comparing them

23. Use comparative terms like bigger, longer, taller, and heavier

24. Recognize patterns or repeating sequences of things in their everyday settings and activities

25. Duplicate simple patterns (e.g., looking at grapes in a red, green, red, green pattern and using two different colored cheese cubes to make the same alternating pattern)

26. Create simple patterns

27. Add and subtract to 10

28. Add and subtract to 20

29. Play computer games, apps or visit interactive websites that include number games

30. Discuss patterns in days of the week, months of the year, or seasons 


\section{References}

1. Duncan, G.J.; Dowsett, C.J.; Claessens, A.; Magnuson, K.; Huston, A.C.; Klebanov, P.; Pagani, L.S.; Feinstein, L.; Engel, M.; Brooks-Gunn, J.; et al. School readiness and later achievement. Dev. Psychol. 2007, 43, 1428-1446. [CrossRef]

2. Eason, S.H.; Scalise, N.R.; Berkowitz, T.; Ramani, G.B.; Levine, S.C. Reviewing the Family Math Literature: Recommendations for Practice, Policy, and Research. White paper, 2020; Family Math Roadmap Implementation Project. Available online: https:/ / education-first.com/wp-content/uploads/2020/06/FamilyMathReview_WhitePaper.pdf (accessed on 20 June 2021).

3. Hornburg, C.B.; Borriello, G.A.; Kung, M.; Lin, J.; Litkowski, E.; Cosso, J.; Ellis, A.; King, Y.; Zippert, E.; Cabrera, N.J.; et al. Next directions in measurement of the home mathematics environment: An international and interdisciplinary perspective. J. Numer. Cogn. 2021, manuscript accepted for publication. [CrossRef]

4. LeFevre, J.-A.; Skwarchuk, S.-L.; Smith-Chant, B.L.; Fast, L.; Kamawar, D.; Bisanz, J. Home numeracy experiences and children's math performance in the early school years. Can. J. Behav. Sci. 2009, 41, 55-66. [CrossRef]

5. Skwarchuk, S.-L.; Sowinski, C.; LeFevre, J.-A. Formal and informal home learning activities in relation to children's early numeracy and literacy skills: The development of a home numeracy model. J. Exp. Child Psychol. 2014, 121, 63-84. [CrossRef]

6. Kleemans, T.; Peeters, M.; Segers, E.; Verhoeven, L. Child and home predictors of early numeracy skills in kindergarten. Early Child. Res. Q. 2012, 27, 471-477. [CrossRef]

7. Niklas, F.; Schneider, W. Casting the die before the die is cast: The importance of the home numeracy environment for preschool children. Eur. J. Psychol. Educ. 2014, 29, 327-345. [CrossRef]

8. Manolitsis, G.; Georgiou, G.K.; Tziraki, N. Examining the effects of home literacy and numeracy environment on early ready and math acquisition. Early Child. Res. Q. 2013, 28, 692-703. [CrossRef]

9. Blevins-Knabe, B.; Austin, A.B.; Musun, L.; Eddy, A.; Jones, R.M. Family home care providers' and parents' beliefs and practices concerning mathematics with young children. Early Child Dev. Care 2000, 165, 41-58. [CrossRef]

10. DeFlorio, L.; Beliakoff, A. Socioeconomic status and preschoolers' mathematical knowledge: The contribution of home activities and parent beliefs. Early Educ. Dev. 2015, 26, 319-341. [CrossRef]

11. De Keyser, L.; Bakker, M.; Rathé, S.; Wijns, N.; Torbeyns, J.; Verschaffel, L.; De Smedt, B. No association between the home math environment and numerical and patterning skills in a large and diverse sample of 5- to 6-year-olds. Front. Psychol. 2020, 11, 1-13. [CrossRef]

12. Missall, K.; Hojnoski, R.L.; Caskie, G.I.L.; Repasky, P. Home numeracy environments of preschoolers: Examining relations among mathematical activities, parent mathematical beliefs, and early mathematical skills. Early Educ. Dev. 2015, 26, 356-376. [CrossRef]

13. Silinskas, G.; Leppänen, U.; Aunola, K.; Parrila, R.; Nurmi, J.-E. Predictors of mothers' and fathers' teaching of reading and mathematics during kindergarten and Grade 1. Learn. Instr. 2010, 20, 61-71. [CrossRef]

14. Ciping, D.; Silinskas, G.; Wei, W.; Georgiou, G.K. Cross-lagged relationships between home learning environment and academic achievement in Chinese. Early Child. Res. Q. 2015, 33, 12-20. [CrossRef]

15. Elliott, L.; Bachman, H.J. How do parents foster young children's math skills? Child Dev. Perspect. 2018, 12, 16-21. [CrossRef]

16. Zippert, E.L.; Rittle-Johnson, B. The home math environment: More than numeracy. Early Child. Res. Q. 2020, 50, 4-15. [CrossRef]

17. Purpura, D.J.; King, Y.A.; Rolan, E.; Hornburg, C.B.; Schmitt, S.A.; Hart, S.A.; Ganley, C.M. Examining the factor structure of the home mathematics environment to delineate its role in predicting preschool numeracy, mathematical language, and spatial skills. Front. Psychol. 2020, 11, 1-14. [CrossRef] [PubMed]

18. National Research Council. Mathematics Learning in Early Childhood: Paths toward Excellence and Equity; The National Academies Press: Washington, DC, USA, 2009.

19. Purpura, D.J.; Lonigan, C.J. Early numeracy assessment: The development of the Preschool Numeracy Scales. Early Educ. Dev. 2015, 26, 286-313. [CrossRef] [PubMed]

20. Wynn, K. Children's acquisition of the number words and the counting system. Cogn. Dev. 1992, 24, 220-251. [CrossRef]

21. Sarnecka, B.W.; Carey, S. How counting represents number: What children must learn and when they learn it. Cognition 2008, 108, 662-674. [CrossRef]

22. Geary, D.C.; van Marle, K.; Chu, F.W.; Rouder, J.; Hoard, M.K.; Nugent, L. Early conceptual understanding of cardinality predicts superior school-entry number-system knowledge. Psychol. Sci. 2018, 29, 191-205. [CrossRef] [PubMed]

23. Dowker, A. Individual differences in numerical abilities in preschoolers. Dev. Sci. 2008, 11, 650-654. [CrossRef]

24. Nguyen, T.; Watts, T.W.; Duncan, G.J.; Clements, D.H.; Sarama, J.S.; Wolfe, C.; Spitler, M.E. Which preschool mathematics competencies are most predictive of fifth grade achievement? Early Child. Res. Q. 2016, 36, 550-560. [CrossRef] [PubMed]

25. Traverso, L.; Tonizzi, I.; Usai, M.C.; Viterbori, P. The relationship of working memory and inhibition with different number knowledge skills in preschool children. J. Exp. Child Psychol. 2021, 203, 1-21. [CrossRef] [PubMed]

26. Purpura, D.J.; Lonigan, C.J. Informal numeracy skills: The structure and relations among numbering, relations, and arithmetic operations in preschool. Am. Educ. Res. J. 2013, 50, 178-209. [CrossRef]

27. Desoete, A.; Ceulemans, A.; De Weerdt, F.; Pieters, S. Can we predict mathematical learning disabilities from symbolic and nonsymbolic comparison tasks in kindergarten? Findings from a longitudinal study. Br. J. Educ. Psychol. 2012, 82, 64-81. [CrossRef]

28. Fazio, L.K.; Bailey, D.H.; Thompson, C.A.; Siegler, R.S. Relations of different types of numerical magnitude representations to each other and to mathematics achievement. J. Exp. Child Psychol. 2014, 123, 53-72. [CrossRef] [PubMed]

29. Schneider, M.; Beeres, K.; Coban, L.; Merz, S.; Schmidt, S.S.; Stricker, J.; De Smedt, B. Associations of non-symbolic and symbolic numerical magnitude processing with mathematical competence: A meta-analysis. Dev. Sci. 2017, 20, 1-16. [CrossRef] 
30. Jordan, N.C.; Kaplan, D.; Ramineni, C.; Locuniak, M.N. Early math matters: Kindergarten number competence and later mathematics outcomes. Dev. Psychol. 2009, 45, 850-867. [CrossRef]

31. Jordan, N.C.; Levine, S.C. Socioeconomic variation, number competence, and mathematics learning difficulties in young children. Dev. Disabil. Res. Rev. 2009, 15, 60-68. [CrossRef]

32. Litkowski, E.C.; Duncan, R.J.; Logan, J.A.R.; Purpura, D.J. When do preschoolers learn specific mathematics skills? Mapping the development of early numeracy knowledge. J. Exp. Child Psychol. 2020, 195, 1-25. [CrossRef]

33. Chu, F.W.; van Marle, K.; Geary, D.C. Predicting children's reading and mathematics achievement from early quantitative knowledge and domain-general cognitive abilities. Front. Psychol. 2016, 7, 1-14. [CrossRef]

34. Östergren, R.; Träff, U. Early number knowledge and cognitive ability affect early arithmetic ability. J. Exp. Child Psychol. 2013, 115, 405-421. [CrossRef]

35. Canobi, K.H.; Bethune, N.E. Number words in young children's conceptual and procedural knowledge of addition, subtraction, and inversion. Cognition 2008, 108, 675-686. [CrossRef] [PubMed]

36. Barth, H.; Beckmann, L.; Spelke, E.S. Nonsymbolic, approximate arithmetic in children: Abstract addition prior to instruction. Dev. Psychol. 2008, 44, 1466-1477. [CrossRef] [PubMed]

37. Rittle-Johnson, B.; Zippert, E.L.; Boice, K.L. The roles of patterning and spatial skills in early mathematics development. Early Child. Res. Q. 2019, 46, 166-178. [CrossRef]

38. Zippert, E.L.; Clayback, K.; Rittle-Johnson, B. Not just IQ: Patterning predicts preschoolers' math knowledge beyond fluid reasoning. J. Cogn. Dev. 2019, 20, 752-771. [CrossRef]

39. Rittle-Johnson, B.; Fyfe, E.R.; Hofer, K.G.; Farran, D.C. Early math trajectories: Low-income children's mathematics knowledge from ages 4 to 11. Child Dev. 2017, 88, 1727-1742. [CrossRef]

40. Cheung, S.K.; Dulay, K.M.; McBride, C. Parents' characteristics, the home environment, and children's numeracy skills: How are they related in low- to middle-income families in the Philippines? J. Exp. Child Psychol. 2020, 192, 1-19. [CrossRef]

41. Mutaf Yildiz, B.; Sasanguie, D.; De Smedt, B.; Reynvoet, B. Frequency of home numeracy activities is differentially related to basic number processing and calculation skills in kindergarteners. Front. Psychol. 2018, 9, 1-13. [CrossRef]

42. Ramani, G.B.; Rowe, M.L.; Eason, S.H.; Leech, K.A. Math talk during informal learning activities in Head Start families. Cogn. Dev. 2015, 35, 15-33. [CrossRef]

43. Paris, S.G. Reinterpreting the development of reading skills. Read. Res. Q. 2005, 40, 184-202. [CrossRef]

44. Snow, C.E.; Matthews, T.J. Reading and language in the early grades. Future Child. 2016, 26, 57-74. [CrossRef]

45. McCormick, M.P.; Weissman, A.K.; Weiland, C.; Hsueh, J.; Sachs, J.; Snow, C. Time well spent: Home learning activities and gains in children's academic skills in the prekindergarten year. Dev. Psychol. 2020, 56, 710-726. [CrossRef] [PubMed]

46. Missall, K.N.; Hojnoski, R.L.; Moreano, G. Parent-child mathematical interactions: Examining self-report and direct observation. Early Child Dev. Care 2017, 187, 1896-1908. [CrossRef]

47. Hart, S.A.; Ganley, C.M.; Purpura, D.J. Understanding the home math environment and its role in predicting parent report of children's math skills. PLoS ONE 2016, 11, 1-30. [CrossRef]

48. Napoli, A.R.; Purpura, D.J. The home literacy and numeracy environment in preschool: Cross-domain relations of parent-child practices and child outcomes. J. Exp. Child Psychol. 2018, 166, 581-603. [CrossRef]

49. Segers, E.; Kleemans, T.; Verhoeven, L. Role of parent literacy and numeracy expectations and activities in predicting early numeracy skills. Math. Think. Learn. 2015, 17, 219-236. [CrossRef]

50. Zippert, E.L.; Douglas, A.-A.; Smith, M.R.; Rittle-Johnson, B. Preschoolers' broad mathematics experiences with parents during play. J. Exp. Child Psychol. 2020, 192, 1-22. [CrossRef]

51. Rittle-Johnson, B.; Douglas, A.; Zippert, E.; Özel, S.; Tang, J. Early Patterning Assessment. Vanderbilt University, Nashville, TN 37203. 2020. Available online: https://peabody.vanderbilt.edu/departments/psych/research/research_labs/childrens_ learning_lab/IESprojects-and-materials.php (accessed on 21 October 2020).

52. Rittle-Johnson, B.; Fyfe, E.R.; Loehr, A.M.; Miller, M.R. Beyond numeracy in preschool: Adding patterns to the equation. Early Child. Res. Q. 2015, 31, 101-112. [CrossRef]

53. Bachman, H.J.; Degol, J.L.; Elliott, L.; Scharphorn, L.; El Nokali, N.E.; Palmer, K.M. Preschool math exposure in private center-based care and low-SES children's math development. Early Educ. Dev. 2018, 29, 417-434. [CrossRef]

54. Bachman, H.J.; Elliott, L.; Duong, S.; Betancur, L.; Navarro, M.G.; Votruba-Drzal, E.; Libertus, M. Triangulating multi-method assessments of parental support for early math skills. Front. Educ. 2020, 5, 1-18. [CrossRef] [PubMed]

55. Mutaf Yildiz, B.; Sasanguie, D.; De Smedt, B.; Reynvoet, B. Investigating the relationship between two home numeracy measures: A questionnaire and observations during Lego building and book reading. Br. J. Dev. Psychol. 2018, 36, 354-370. [CrossRef] [PubMed] 